\title{
Los resultados del proyecto europeo sobre escultura policromada se presentarán en un Congreso Internacional en octubre
}

El Instituto Andaluz de Patrimonio Histórico ha actuado como anfitrión en la última reunión, celebrada durante los días 14 al 16 de marzo, de los representantes de los países participantes en el Programa Raphael, financiado por la Unión Europea, sobre Escultura Policromada.

Dicho proyecto, coordinado y organizado por el Instituto Portugués de Conservación y Restauración, cuenta con la participación de varias instituciones belgas, portuguesas y españolas. Con él se pretende cubrir el estudio sistemático de carácter científico e interdisciplinar sobre la escultura policromada, así como la falta de criterios de intervención en conservación-restauración capaces de dar respuesta a las nuevas exigencias deontológicas en la salvaguarda de nuestro Patrimonio común.

Cada país participante presenta el estudio de un grupo de esculturas, desarrollándose una investigación interdisciplinar con metodología común, fruto de la cooperación entre los profesionales de las distintas instituciones.

Para sistematizar la información, fruto de las investigaciones realizadas, se ha diseñado una base de datos que se presenta en Internet. Como producto de difusión se está realizando un CD-ROM, en el que se presentarán diversos estudios de una selección de piezas que se incluyen en el proyecto. Los resultados del proyecto serán expuestos en un Congreso Internacional que se celebrará en Lisboa durante los días 29 al 31 de octubre de 2002.
El grupo de participantes acordó efectuar una serie de reuniones periódicas e itinerantes entre las distintas instituciones que forman parte del proyecto, como las desarrolladas en el Institut Royal du Patrimoine Artístique, Musée de Louvain La Neuve, Museu de Aveiro, Instituto del Patrimonio Histórico Español, Museu Nacional Machado de Castro. La que nos ocupa fue la VII reunión, segunda y última que se realiza en Sevilla.

La reunión quedó estructurada en una primera jornada dedicada a la presentación y demostración del CD-ROM que se encuentra en fase de desarrollo e implementación.

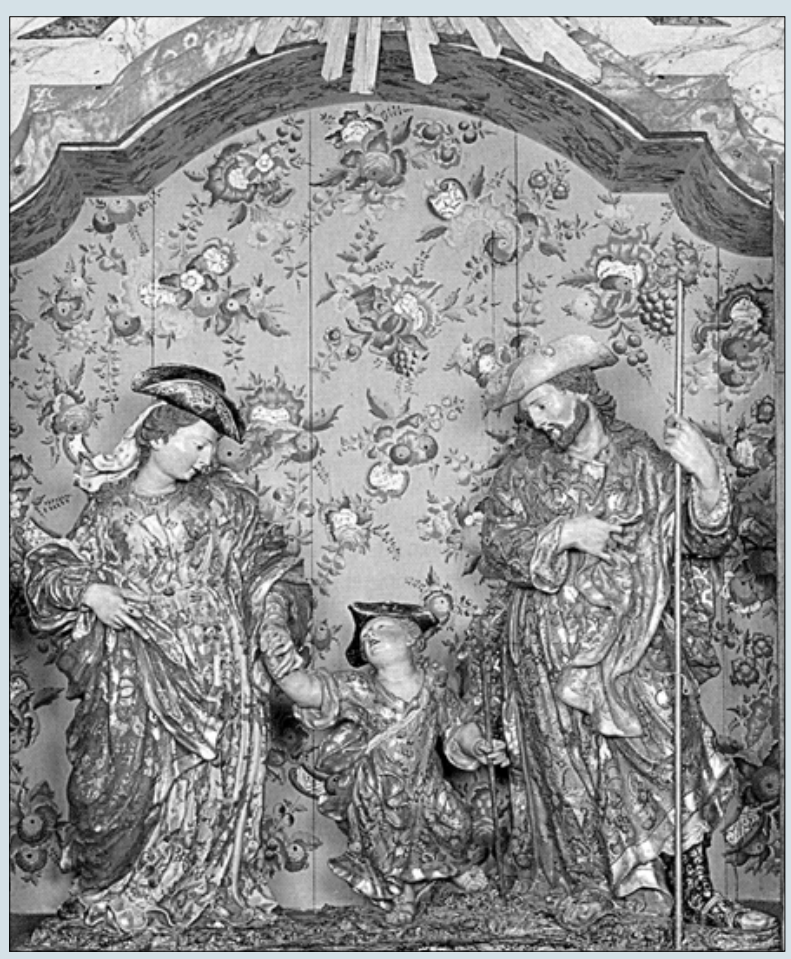

La segunda jornada fue dedicada a establecer las comunicaciones a presentar en el Congreso de Lisboa, así como a la revisión de los problemas detectados en el funcionamiento de la base de datos.

La tercera jornada estuvo dedicada al establecimiento de las conclusiones generales entre las que destaca: la importancia de presentar una demo más profunda del CD-
ROM y finalizar la cumplimentación de la base de datos. También se fijaron los temas a tratar en la próxima reunión que tendrá lugar del II al 13 de julio en Lisboa.

Antonio Martín Pradas

Área de Normalización Terminológica Centro de Documentación del IAPH

\section{La AECl abre el plazo de solicitud de ayudas para la cooperación cultural}

El Boletín Oficial del Estado del pasado 15 de marzo $\left(n^{\circ} 64\right)$ recogía la convocatoria de ayudas 2002 para la financiación de actividades de cooperación al desarrollo y de promoción económica y social, cultural, técnica, científica, profesional o asistencial relacionadas con los fines y funciones de cooperación de la Agencia Española de Cooperación Internacional. Podrán optar a estas ayudas per- sonas físicas y jurídicas españolas o extranjeras, para actividades tanto en España como en otros países.

El plazo de presentación de solicitudes estará abierto a lo largo de todo el año, estableciéndose el I de diciembre como fecha límite para la admisión de la documentación, por razones presupuestarias.
Información:

Agencia Española de Cooperación Internacional Avda. Reyes Católicos, 4 28040 Madrid

Web: www.aeci.es 